\title{
LA PRESENCIA DE LAS GRANDES MARCAS EN LA FICCIÓN ESPAÑOLA: EL CASO DE COCA-COLA EN EL BARCO DE
} ANTENA 3

\author{
Fernández Gómez, Erika \\ Universidad Internacional de la Rioja (UNIR) \\ erika.fernandez@unir.net
}

Material original autorizado para su primera publicación en la revista académica REDMARKA. Revista Digital de Marketing Aplicado.

https://doi.org/10.17979/redma.2013.01.011.4750

Recibido: 23 Octubre 2012

Aceptado: 14 Diciembre 2012

\section{RESUMEN}

En este artículo se presenta cómo las marcas se integran en la ficción Española incluso llegando a adaptarse por ellas el guión. También se muestra cómo son capaces de traspasar de la pequeña pantalla a otros medios. Para ello, se ha realizado un análisis de contenido cuantitativo-cualitativo de la primera temporada de la serie, El Barco. Se trata de una producción de Globomedia emitida en el prime time de la cadena generalista privada Antena 3. Se ha seleccionado esta ficción como objeto de estudio ya que, registró una media de 4,2 millones de espectadores y contó con el product placement de una de las grandes marcas: Coca-cola.

Palabras clave: Product placement, ficción española y publicidad.

\section{ABSTRACT}

THE PRESENCE OF BIG BRANDS IN THE SPANISH FICTION: THE CASE OF COCA-COLA IN EL BARCO OF ANTENA 3.

This paper shows how brands fit in Spanish fiction. Sometimes, the script is reviewed in order to promote a product. It also presents how brands can go through the small screen to other media. For this reason, it was carried out a 
content analysis from a qualitative and quantitative point of view from the first season of the series, El Barco. This show was produced by Globomedia and broadcast during the prime time in the private channel Antena 3. It was chosen this production as al result of the audience registered. It had an average of 4,2 million of spectators and it had the product placement of one of the biggest brands in the world: Coca-cola.

\section{Key words}

Product placement, Spanish fiction and advertising- 


\section{INTRODUCCIÓN}

En 2011, la inversión publicitaria en medios convencionales fue mayor que en los convencionales (Infoadex, 2012, p.10). De modo que, la industria publicitaria se ha decantado por acciones below-the-line. En el caso de los convencionales, mientras la televisión, la prensa o la radio, entre otros, disminuyen cada año sus ingresos publicitarios, los medios digitales experimentaron un crecimiento del 12,6\% entre el año 2010 y 2011. En total, los medios digitales ingresaron 899,24 millones de euros (IAB Spain y PwC, 2011).

Así, aunque el crecimiento de Internet sigue imparable, la televisión continúa siendo el medio líder en audiencias. Cuenta con una penetración en la población española del 88,9\% (AIMC, 2011-2012). Y, además, es líder en volumen de negocio entre los medios convencionales. Le corresponde el $40,6 \%$ del pastel publicitario (Infoadex, 2012, p.9).

En la pequeña pantalla, las series de ficción nacional son el tercer producto más visto por parte de la audiencia. Los acontecimientos deportivos, entre ellos el futbol, y los informativos lideran las preferencias de los espectadores (FAPAE, 2011, p.121). Durante casi todos los meses del año, entre las cinco emisiones más vistas de las principales cadenas se encuentra una serie española.

Este es el caso, por ejemplo, de la cadena generalista privada, Antena 3. La serie El Barco alcanzó en la despedida de su primera temporada en abril de 2011, un 23\% de cuota. Unos 4,2 millones de espectadores (FAPAE, 2011, p.123).

Ante este panorama, no es de extrañar que las marcas traten de estar presentes en uno de los productos audiovisuales más rentables de la televisión. 
En el caso de El Barco, un cataclismo mundial obliga a la tripulación y alumnos del buque-escuela Estrella Polar a vivir aislados y sin rumbo. A pesar de esta falta situación, hay una cosa que nunca falta a bordo: Coca-Cola.

\section{OBJETIVOS Y METODOLOGÍA}

El objetivo de este estudio ha sido analizar cómo la marca americana se integra en la ficción española. Se persigue determinar el número de inserciones de la bebida, cómo es esta presencia en la pantalla y qué papel juega en la definición de los personajes y la trama.

De modo que se parte de cuatro objetivos específicos:

- Analizar el tipo de product placement realizado por Coca-cola.

- Relacionar esos emplazamientos con el argumento de la serie, las localizaciones en las que se insertan y el público objetivo al que se dirigen.

- Interpretar la finalidad del emplazamiento (para reforzar la marca, el posicionamiento, introducir una nueva forma de consumo, etc.).

- Sondear la percepción de los espectadores.

Por lo que se plantea la siguiente hipótesis:

- Coca-Cola empela esta fórmula publicitaria para reforzar su posicionamiento en la mente del consumidor.

Para llevar a cabo el estudio se ha realizado un análisis de contenido de la primera temporada de esta serie, compuesta por 13 capítulos. 
Se ha procedido a la clasificación y descripción sistemática de los emplazamientos según los siguientes indicadores: marca, producto, secuencia, tipo de product placement y duración ${ }^{1}$.

En la Tabla 1 se pueden ver los tipos de product placement en función del grado de interacción, el tipo de presencia y la relación con el contexto.

Tabla 1. Clasificación del product placement

\begin{tabular}{|c|c|c|}
\hline Tipo de emplazamiento & $\begin{array}{l}\text { Tipo de presencia: } \\
\text { ubicación }\end{array}$ & $\begin{array}{l}\text { Relación con el contexto } \\
\text { (personajes y escenarios) }\end{array}$ \\
\hline $\begin{array}{l}\text { Hiperactivo: la marca es el } \\
\text { detonante de la trama. } \\
\text { Interacción marca y actor. } \\
\text { - Valoración: el actor } \\
\text { interactúa y valora. } \\
\text { - Mención: el actor menciona } \\
\text { pero no valora. }\end{array}$ & $\begin{array}{l}\text { Protagonista: primera } \\
\text { línea visual, delante del } \\
\text { personaje. }\end{array}$ & $\begin{array}{l}\text { Definidor: la marca } \\
\text { caracteriza al personaje o } \\
\text { lo enriquece. }\end{array}$ \\
\hline $\begin{array}{l}\text { Activo: interacción actor y } \\
\text { marca. No existe valoración ni } \\
\text { mención. }\end{array}$ & $\begin{array}{l}\text { Neutro: se puede } \\
\text { identificar y distinguir la } \\
\text { marca, pero no acapara } \\
\text { el protagonismo. }\end{array}$ & $\begin{array}{l}\text { Natural: no añade nada } \\
\text { definidor. El } \\
\text { emplazamiento está } \\
\text { justificado y es pertinente. }\end{array}$ \\
\hline $\begin{array}{l}\text { Pasivo: mera visualización, no } \\
\text { interacción. } \\
\text { - Principal: aportación } \\
\text { pertinente. } \\
\text { - Secundario: elemento } \\
\text { figurativo. }\end{array}$ & $\begin{array}{l}\text { Fondo: la marca ocupa } \\
\text { un lugar secundario. }\end{array}$ & $\begin{array}{l}\text { Indiferente: no aporta ni } \\
\text { guarda relación. }\end{array}$ \\
\hline \multirow[t]{2}{*}{$\begin{array}{l}\text { Verbal: mención del actor sin } \\
\text { interacción. } \\
\text { - Valoración: el actor } \\
\text { menciona y opina. } \\
\text { - Mención: el actor nombra } \\
\text { sin más. }\end{array}$} & & $\begin{array}{l}\text { Artificial: opuesto al } \\
\text { natural. }\end{array}$ \\
\hline & & Contradictorio: niega un \\
\hline
\end{tabular}

\footnotetext{
${ }^{1}$ La duración hace referencia al emplazamiento por secuencia, es decir, tiempo que trascurre desde el primer plano hasta el último en el que aparece.
} 
rasgo básico.

Tabla: Elaboración propia $\quad$ Fuente: Del Pino, Cristina (enero-diciembre2006)

Posteriormente, se describen los emplazamientos más representativos de la marca encontrados en cada capítulo. De modo que el análisis se realiza tanto desde una perspectiva cuantitativa como cualitativa.

Finalmente, para tener una visión sobre la percepción de la marca por parte de los espectadores se ha procedido a realizar una búsqueda en la red social Facebook a través de dos palabras clave: "Coca-Cola y El Barco".

\section{FICCIÓN Y PUBLICIDAD}

\subsection{El product placement como formato publicitario}

Ya desde la veterana Farmacia de Guardia, emitida en Antena 3 en 1991, el product placement o brand placement ha sido una práctica habitual en las series españolas.

Del Pino y Olivares definen el product placement o brand placement como:

"toda referencia o presencia audiovisual, verbal o visual, explícita e intencional de una marca (de producto o empresa; individual, sectorial o mancomunada; de persona física o jurídica), claramente identificable, lograda mediante una gestión y una negociación con la productora de contenidos, en el contexto espacial o narrativo del género de la ficción, especialmente cinematográfica y televisiva, al margen de la plataforma física por la que se emita" (Del Pino y Olivares, 2006, p.55).

La Ley 7/2010, de 31 de marzo, General de la Comunicación Audiovisual define el emplazamiento de producto y contempla su uso como técnica comercial en series de televisión (2010, p.30165): "Toda forma de comunicación comercial audiovisual consistente en incluir, mostrar o referirse a un producto, servicio o marca comercial de manera que figure en un programa". 
Además, en el artículo 17 se recoge el derecho al emplazamiento de productos en las series de televisión. Si bien se establece con las siguientes condiciones:

- El público debe ser informado del emplazamiento del producto al principio y al final del programa, y cuando se reanude tras una pausa publicitaria.

- El emplazamiento no puede condicionar la independencia editorial.

- Tampoco puede incitar directamente la compra o arrendamientos de bienes o servicios, realizar promociones concretas de éstos o dar prominencia indebida al producto.

\subsection{La ficción Española como vehículo publicitario}

Las series de ficción nacional representan el mejor vehículo para llegar al consumidor.

En primer lugar, son el tipo de programa con mayor presencia en la parilla de las cadenas y que mayores audiencias registra (FAPAE, 2011, p.121). En segundo lugar, permiten un impacto más efectivo lejos del ruido de la competencia. Asimismo, gracias a la variedad de contenidos y de personajes, consiguen establecer una identificación con un amplio perfil de público (Del Pino y Olivares, 2006, p.346). Además de que son productos que cuentan con otras ventanas de explotación (televisión a la carta, móvil, DVD, etc.).

En el caso de la ficción del prime time, se caracteriza por concentrar al público familiar. De modo que atrae a un gran número de anunciantes, especialmente procedentes de los sectores de: alimentación, bebidas, juegos, entretenimiento familiar o ropa para jóvenes. La mayoría de los productos aparecen en la mesa de la cocina y durante el desayuno ya que, las marcas comestibles se vinculan a ese momento y lugar de consumo (Codina, 2008, pp.104-112). A medida que 
los escenarios se diversifican, se amplía la gama sectorial de los emplazamientos.

Para la industria también tiene sus ventajas. Supone un modo de financiación, proporciona realismo, ayudan a la caracterización de los personajes y contribuye a la ambientación histórica. Por ejemplo, en el caso de Cuéntame de $\mathrm{TVE}^{2}$, las marcas son fundamentales para situarnos en una determinada época (Baños y Rodríguez, 2012, p.15).

\section{PANORAMA PUBLICITARIO Y AUDIOVISUAL}

\subsection{El mercado publicitario español en el año 2011}

En 2011, la inversión real estimada fue un 6,5\% menos que en 2010. Los medios no convencionales superaron a los convencionales, quienes se llevaron un $54,4 \%$ del pastel publicitario frente al 45,6\% del conjunto de la televisión, la radio, revistas o dominicales. Solo cine e internet, también convencionales, vieron crecer sus ingresos en términos publicitarios (Infoadex, 2012, p.10).

En el caso de la pequeña pantalla, continúa siendo el primer medio en volumen de negocio (40,6\%). Pero perdió un 1,7\% de participación respecto al conjunto de medios convencionales.

Las televisiones nacionales en abierto concentraron el $88,3 \%$ del total de la inversión recibida por el medio. Si bien, perdieron un 7,1\% respecto a 2010 . Por grupos, Telecinco es el primero en inversión publicitaria (975 millones de euros) seguida por Antena 3 (681,5 millones de euros).

\footnotetext{
2 Serie que cuenta las vivencias de una familia de clase media durante los últimos años del franquismo y los comienzos de la Transición Española.
} 
Entre los primeros veinte anunciantes por volumen de inversión se encuentran: Procter \& Gamble, Telefónica, El Corte Inglés, L'Oreal, Volkswagen-Audi y Vodafone. Coca-Cola ocupa el decimotercero puesto con 36,1 millones de euros frente a los 123,8 invertidos del primer anunciante en el ranking.

\subsection{Antena 3: El Barco}

Antena 3 contribuyó a que en la década de los 90 la ficción televisiva de producción nacional experimentara un auge sin precedentes. Fue pionera con series como: Farmacia de Guardia (1991), Lleno por favor (1993), Los Ladrones van a la oficina (1993) o Hermanos de leche (1993) (García de Castro, 2002, pp.120-121).

En 2011, según el índice de imagen GECA, se situó como la cadena más innovadora y la cadena privada mejor valorada. Este estudio destacó también la oferta de las mejores series nacionales de las cadenas comerciales y con los actores de mayor calidad.

La cadena del Grupo Planeta es líder entre el público joven, segmento en el que promedió un $23,8 \%$ de cuota. En el caso concreto del canal, registra una media del 12,7\% en este segmento (Antena 3, 2011, p. 61).

\subsubsection{Audiencias}

El Barco, producida por Globomedia $^{3}$, se programó en el prime time de los lunes desde enero a abril de 2011.

La primera temporada registró una media del $20,6 \%$ de cuota de pantalla y una media de 4.139.000 espectadores.

\footnotetext{
${ }^{3}$ Nacida en 1993, se ha convertido en la primera empresa española en el campo de la producción de ficción (Bardají y Gómez, 2004, p.62)
} 
Se trata de un producto respaldado por todos los públicos menores de 64 años, pero en el que destaca un target comercial muy interesante: los jóvenes de 13 a 24 años. En este grupo de audiencia obtuvo una cuota del 35\% (Fórmula TV, 2011). Si bien debe destacarse que, es una producción no recomendada para los menores de 7 años.

El estreno se convirtió en el tercero más exitoso de la temporada. Por delante, sólo se situaron dos ficciones de La Primera de TVE y de la misma productora que El Barco: Cuéntame cómo pasó (5.171.000 espectadores) y Águila Roja (5.523.000).

Además, lideró la noche de los lunes frente a la oferta de la competencia basada también en ficción: 14 de abril. La República de La 1 y CSI de Telecinco. De modo que fue la mejor serie con publicidad ya que, desde 2010 la televisión pública no cuenta con espacios comerciales.

Además, se trata de una serie por la que se ha interesado el mercado internacional. De hecho, se puede ver en varios territorios bálticos (FAPAE, 2011, p.93).

\subsubsection{Sinopsis y personajes}

La tripulación de un buque escuela debe sobrevivir a la catástrofe que ha acabado con el resto del mundo.

Se trata de un dramedia propio del género español, es decir, mezcla tramas melodramáticas con otras de carácter cómico y cuenta con una duración de 70 minutos (Medina, 2008, p.30). Combina la comedia, el drama, el amor y el misterio en una gran historia de aventuras en alta mar. 
Cuenta con un reparto especialmente joven que forma la tripulación del "Estrella Polar",

\section{Personajes masculinos adultos}

- Ricardo Montero, el capitán del Estrella Polar. Un hombre heroico e intachable, con una reputación que le precede.

- De la Cuadra, la mano del capitán. Un hombre de gran experiencia y formación marítima que no estudió pero lo sabe todo sobre el mar. En el barco descubre que el polizón Ulises es su hijo.

- Burbuja. Era marino y tuvo un accidente que le causó importantes lesiones en el cerebro.

- Gamboa. Un hombre atractivo y guapo pero su pasado militar le ha dado un carácter de hierro y muy pocos escrúpulos.

\section{Personajes masculinos jóvenes}

- Ulises es un polizón rebelde y con madera de héroe.

- Andrés Palomares, es el cura.

- Piti, tiene como prioridad ligar.

- Ramiro tiene una malformación en la pierna que le produce una cojera permanente.

\section{Personajes femeninos adultos}

- Julia, la científica. Segura de sí misma y reflexiva.

- Salomé, la cocinera y madre de todos.

\section{Personajes femeninos jóvenes}

\footnotetext{
4 Información obtenida de la web oficial de la serie: http://www.antena3.com/series/el-barco/sobre-serie/personajes/
} 
- Ainhoa, la hija adolescente del capitán que ha embarcado junto a su hermana pequeña Valeria tras el fallecimiento de su madre.

- Valeria, la hija pequeña del capitán.

- Vilma, una chica dura que está embarazada.

- Estela, una alumna tranquila y romántica.

\subsection{Coca-cola}

A estas alturas a nadie se le escapa quién es Coca-cola. No es solo un refresco inventada en 1886 por un farmacéutico de Atlanta (Estados Unidos). Sino que, es la mayor compañía mundial de bebidas, que ofrece a los consumidores 500 marcas de refrescos con y sin gas.

En 2011, en un contexto de incertidumbre económica mundial, continuó siendo la marca más valiosa según el estudio realizado por la consultora Interbrand, posición en la que lleva desde el año 2000.

"Pero Coca-Cola no está dentro del grupo de marcas que pierden valor, sino todo lo contrario. La que es tal vez la marca más reconocible del planeta sigue siendo la más valiosa, o al menos así se desprende del estudio realizado por la consultora Interbrand, donde encabeza el ranking de las marcas globales más valiosas por delante de Apple e IBM" (El Publicista, 2012, p. 5).

En España, es la marca más vinculada a la felicidad. El $45,5 \%$ de los consumidores españoles menciona Coca-cola de forma espontánea cuando se le pregunta qué marca comercial relaciona con la felicidad. Al preguntar a los encuestados si Coca-cola es una marca que asocian con la felicidad, el $89,8 \%$ responden de manera afirmativa (El Publicista, 2012, p.12). 
La propia marca resume de este modo en su web su misión: "refrescar al mundo, inspirar momentos de optimismo y felicidad y crear valor y marcar la diferencia"5.

Además, cuenta con la iniciativa de El Instituto Coca-Cola de la Felicidad, que pretende investigar y la difundir conocimientos sobre la felicidad con el fin de contribuir a mejorar la calidad de vida de los españoles ${ }^{6}$.

Queda claro, por tanto, que la compañía y su bebida estrella han sabido encontrar una única promesa que hacerle de forma clara al target. Así, el beneficio que obtiene el consumidor es la felicidad. Una ventaja competitiva que queda patente en el eslogan iniciado por la marca en 1972: "La chispa de la vida":

Algunos anuncios en televisión vinculados a la felicidad fueron:

- "La fábrica de la felicidad" es el título del spot más largo lanzado por Coca-cola en España con una duración de 3 minutos y 34 segundos. Fue emitido en Navidad del año 2007 y también en 2008.

- En 2009 lanzó el eslogan mundial "Open Happiness" (Destapa la felicidad). El spot lanzaba el siguiente mensaje: "Estás aquí, para ser feliz".

- Con motivo de los 125 años de la marca, en 2011, proyectó una campaña publicitaria con el eslogan: "Hay razones para creer en un mundo mejor".

\section{RESULTADOS}

5 Véase: http://conoce.cocacola.es/conocenos

${ }^{6}$ Véase: http://www.institutodelafelicidad.com/instituto 


\subsection{Análisis cuantitativo}

El análisis del product placement de Coca-cola en la serie El Barco ha arrojado un total de 31 emplazamientos. La marca ha estado presente a lo largo de toda la temporada menos en tres capítulos (tercero, quinto y decimotercero).

La primera temporada contó con un total de 19,38 minutos en los que los diferentes envases de Coca-cola estuvieron en pantalla.

Tabla 2. Número de emplazamientos y capítulos

\begin{tabular}{|l|l|l|}
\hline Marca & Total de emplazamientos & № de capítulos \\
\hline Coca-cola & 31 & $1,2,4,6,7,8,9,10,11,12$ \\
\hline
\end{tabular}

Tabla: Elaboración propia $\quad$ Fuente: elaboración propia

En relación al tipo de emplazamiento (Gráfico 1), la presencia de la marca en la ficción se caracteriza por realizarse de forma accesoria. Es decir, el $61 \%$ de las inserciones se hacen de forma pasiva-secundaria en la que Coca-cola es un elemento figurativo o de atrezzo. Si bien, el segundo tipo de presencia es la activa. Es decir, en el $23 \%$ de los casos existe manipulación e interacción entre marca y actor. En tercer lugar, en el $13 \%$ de las ocasiones el personaje menciona la marca sin realizar una valoración sobre ella. Por último, en un 3\% el actor no interactúa con Coca-cola pero su presencia en la escena es una aportación pertinente a la acción.

\section{Gráfico 1. Tipo de emplazamiento.}




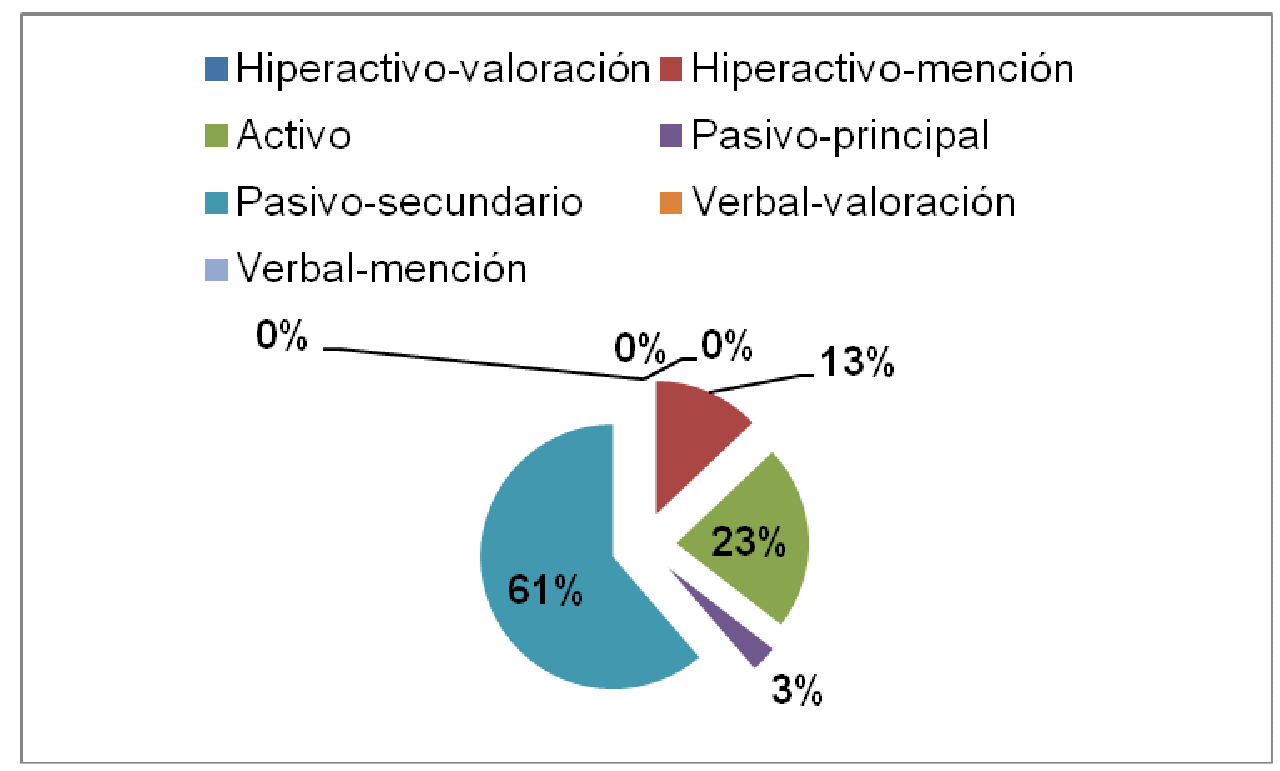

Gráfico: Elaboración propia Fuente: elaboración propia

Gráfico 2. Tipo de presencia.

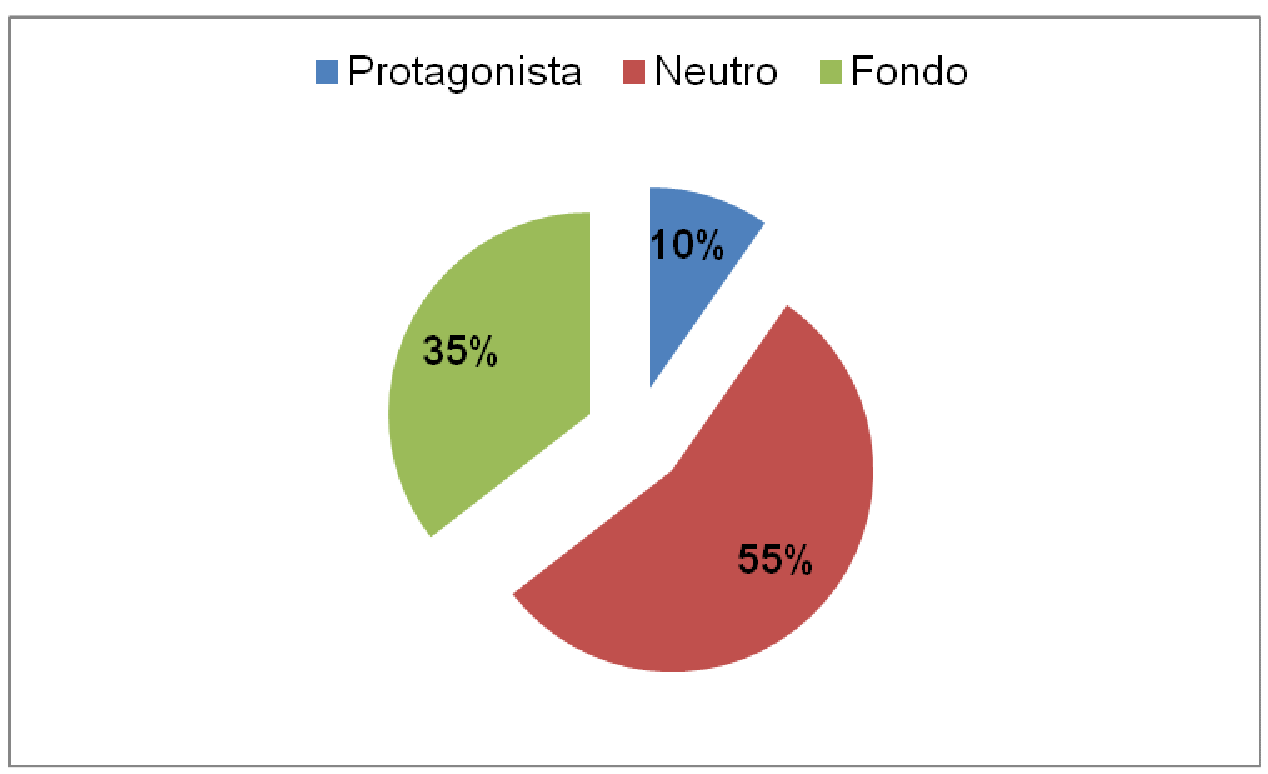

Gráfico: Elaboración propia Fuente: elaboración propia

Atendiendo al lugar que la marca y sus productos ocupan en pantalla, Cocacola se caracteriza por situarse en el $55 \%$ de las escenas en un plano neutro. Es decir, marca y acción se sitúan en la misma línea. En un 35\% de los casos 
se ubica al fondo y en un $10 \%$ adquiere relevancia convirtiéndose en protagonista.

\section{Gráfico 3. Relación con el contexto.}

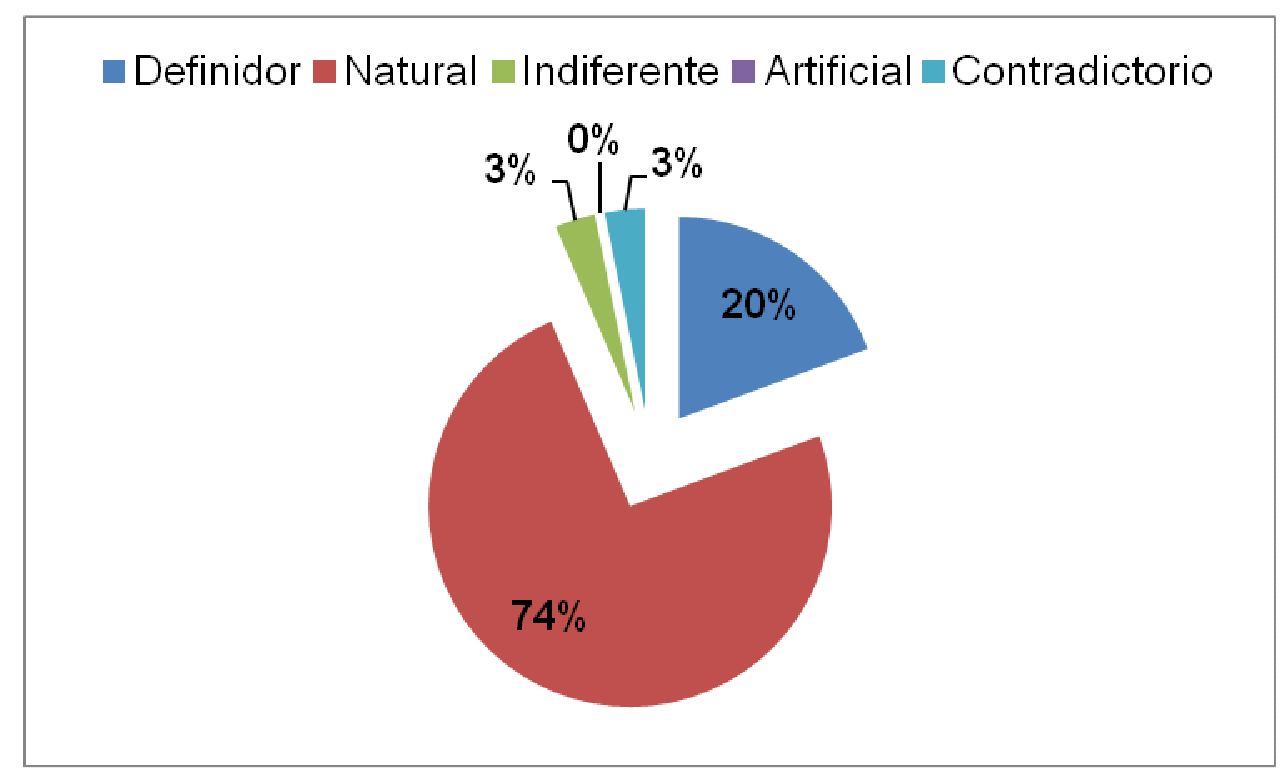

Gráfico: Elaboración propia Fuente: elaboración propia

Sobre la relación que existe entre el emplazamiento de producto y el contexto narrativo, a pesar del gran número de inserciones de la marca, el $74 \%$ son naturales. Es decir, la aparición de Coca-cola en esta primera temporada es pertinente. Además, un $20 \%$ de las escenas en las que aparece contribuyen a definir al personaje. Solamente un $3 \%$ se considera artificial y otro $3 \%$ contradictorio. No hay ningún emplazamiento artificial, es decir, en el que el contexto no sea pertinente.

\section{Gráfico 4. Tipo de producto.}




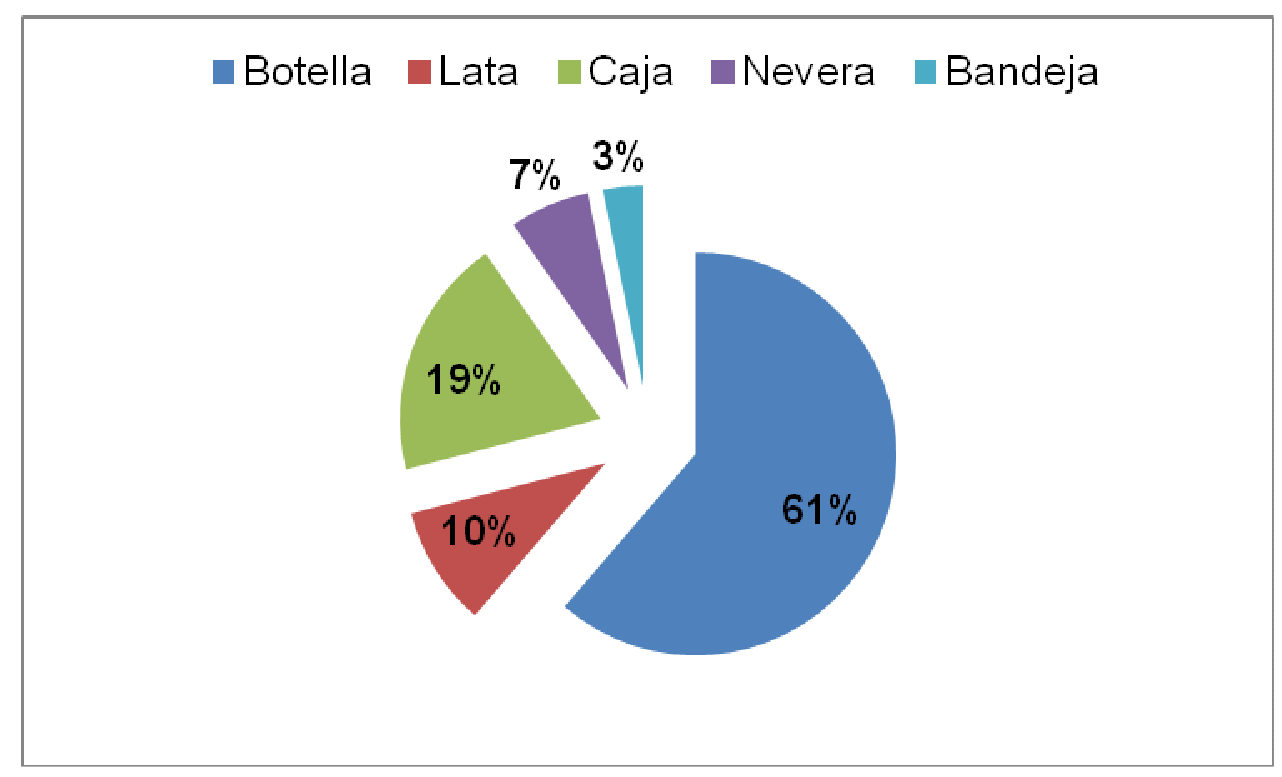

Gráfico: Elaboración propia Fuente: elaboración propia

Todos los emplazamientos se caracterizan por la presencia del producto de la marca, es decir, la bebida. El envase que aparece un mayor número de veces, en el $61 \%$ de las ocasiones, es la botella de vidrio. En segundo lugar, las cajas que contienen el refresco (19\%). La lata se muestra en el $10 \%$ de las ocasiones. Otros productos que muestran la marca son accesorios como la nevera o la bandeja.

Por último, el número medio de planos por secuencia en los que aparece la marca ha sido de 2,84. Es decir, se dedicaron aproximadamente tres planos a Coca-cola en la ficción de Antena 3.

\subsection{Descripción cualitativa}

En el primer capítulo de la temporada ya aparece Coca-cola. El episodios "Un millón de millas" introduce a los personajes y la trama a los espectadores. Al final de esta primera entrega, el capitán les dice a los alumnos que se relajen y se tomen una cerveza. Vilma está tomando el sol y del cubo donde tienen las bebidas a refrescar, saca una lata. La protagonista cace referencia a lo bien que se está tumbada en la toalla y se toma una Coca-cola. Mientras los 
estudiantes se divierten se enfoca varias veces la lata, asociando así la bebida a momentos de diversión y disfrute. Se trata también de un emplazamiento definidor porque, este personaje podría haberse tomarse otro refrigerio como la cerveza propuesta por el capitán.

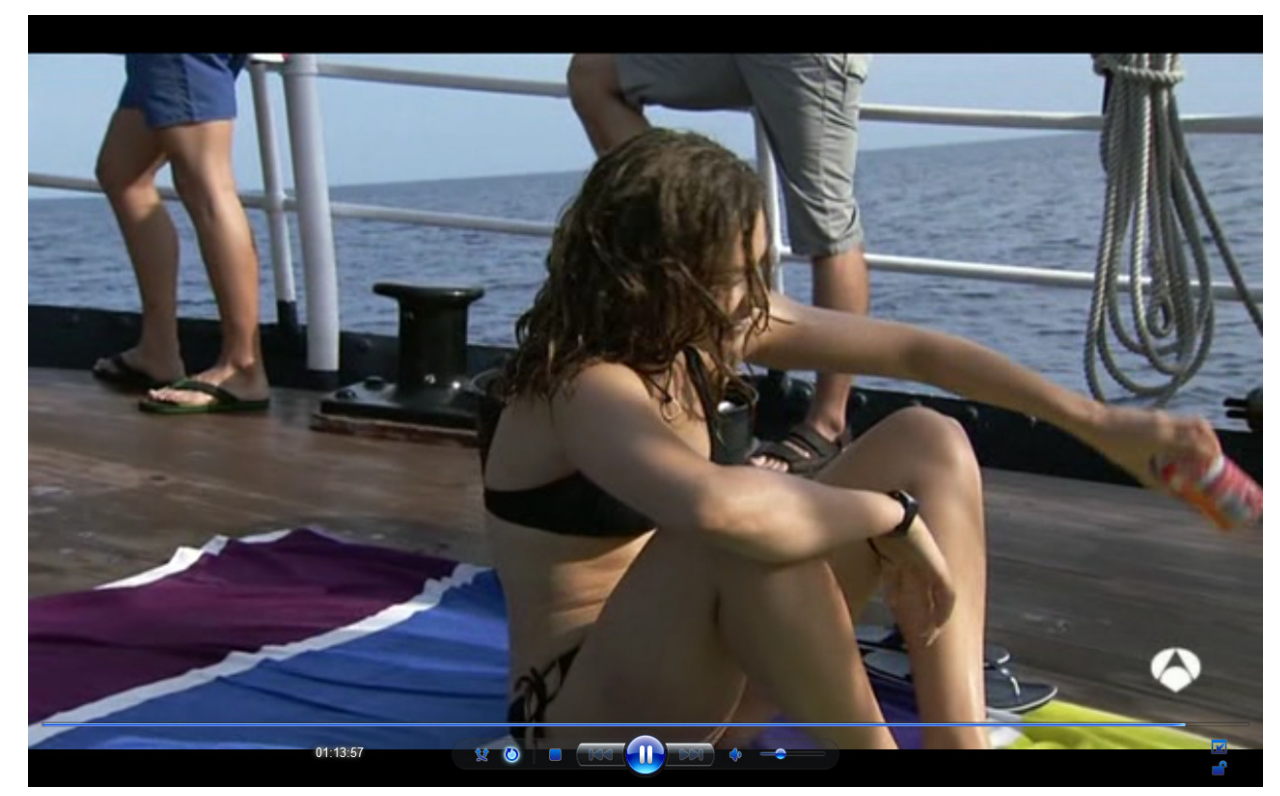

En el segundo capítulo, "Echando la caña", los tripulantes comienzan sus rutinas. El product placement que aparece es el característico de las series familiares: productos de alimentación. En la cocina se aprecia la caja con botellas de Coca-cola. De modo que, se integra formando parte del decorado. Se introduce de forma natural al tiempo que contribuye a situar la escena. Por otro lado, la tripulación acaba de descubrir que el mundo que conocían ha desaparecido. Pero Burbuja y Salomé ven el lado positivo: pueden inventar lo que ellos quieran. Así, Burbuja se pide inventar la Coca-cola. 


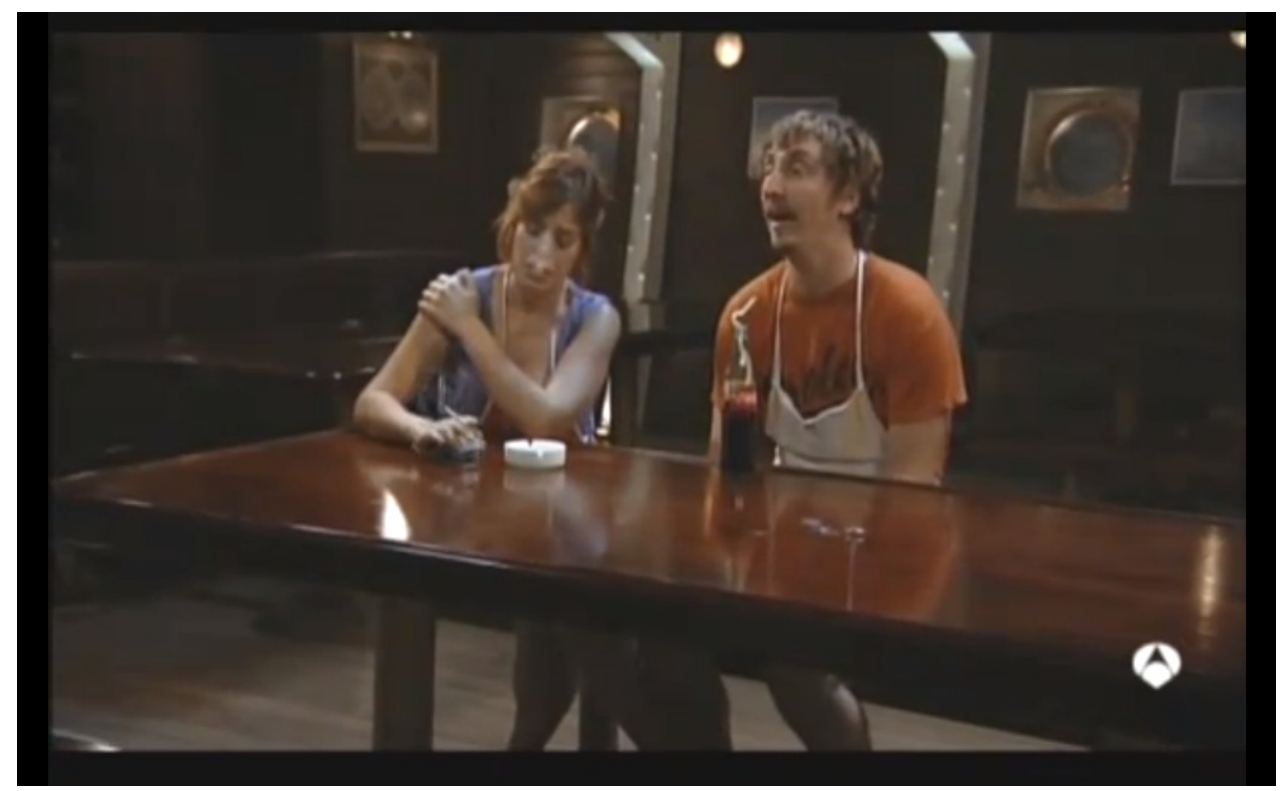

En el cuarto capítulo, "Un mundo bajo el mar", tras saber que la tierra ha desaparecido la tripulación comienza poco a poco a recuperar la normalidad. Fiti propone organizar citas para que los supervivientes se conozcan. En este momento de entretenimiento de los personajes, especialmente de los más jóvenes, la bebida seleccionada es Coca-cola. Ulises pide una en el bar y Salomé se la sirve.

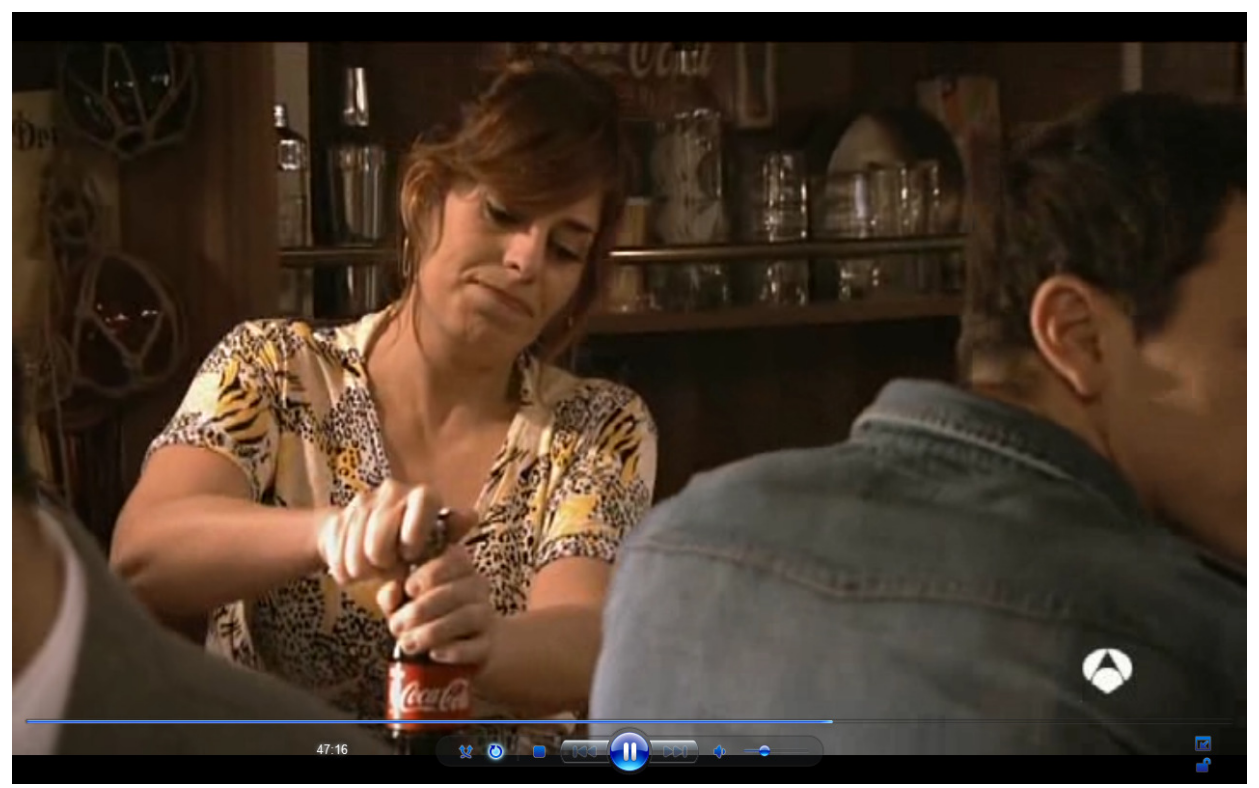

Los nervios comienzan a aflorar en el sexto capítulo, "Elecciones". La causa es la racionalización de comida. Ainhoa emplea una botella de Coca-cola para 
lanzar un mensaje al mar y De la Cuadra y Salomé deciden abrir una botella para relajarse.

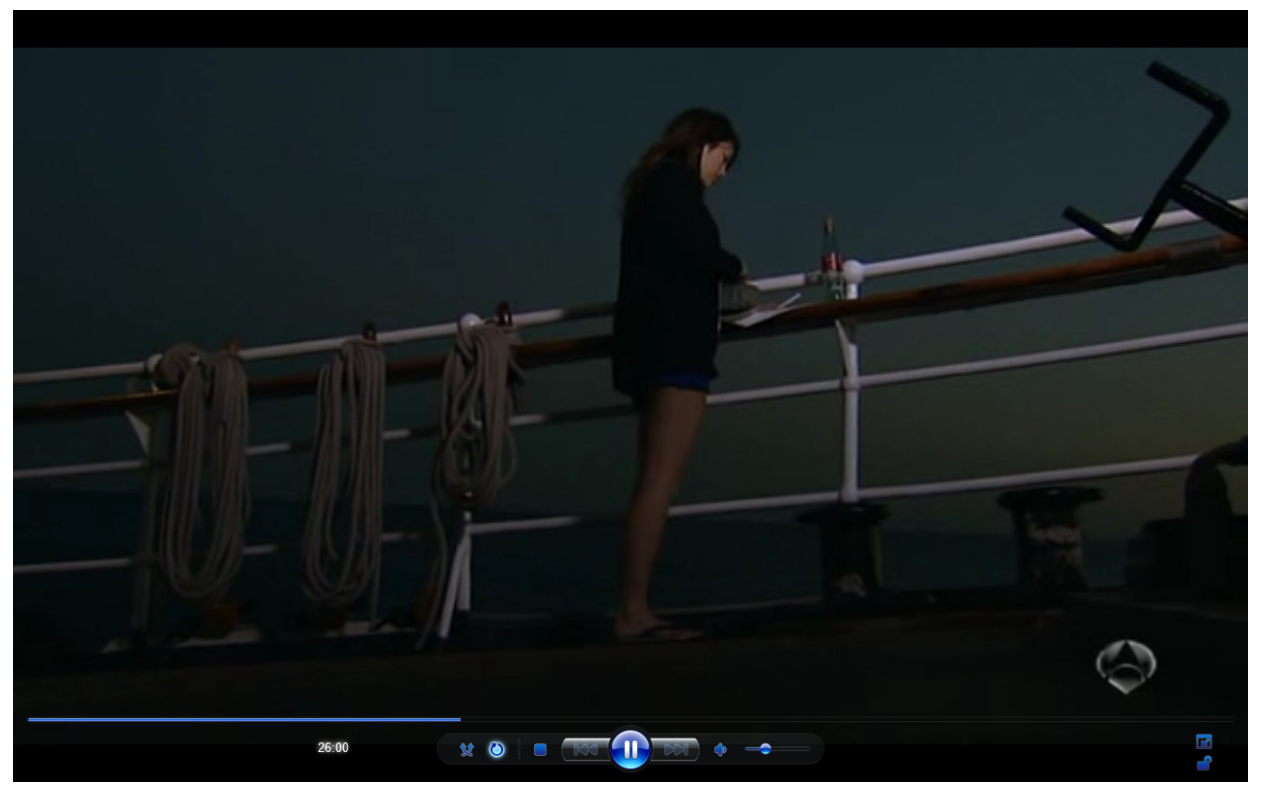

En "Perdidos", la séptima entrega, Ramiro trata de buscar respuestas por su cuenta. Baja a la bodega del buque para tratar de poner en marcha un ordenador. Una de las cajas almacenadas de Coca-cola le sirve de apoyo.

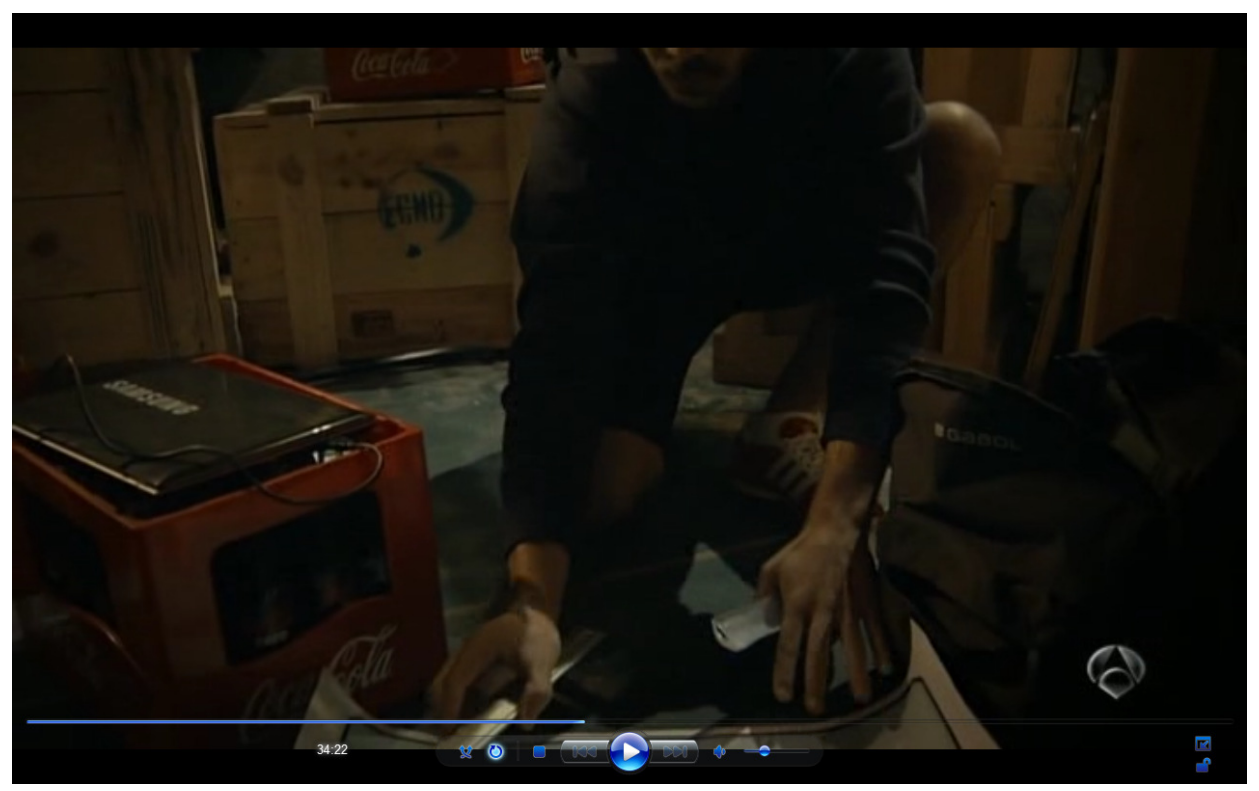

Además, Vilma se toma nuevamente esta bebida. Pero en este caso con un momento de consumo diferente ya que, está sola y triste. De modo que, el 
emplazamiento resulta contradictorio y forzado ya que, en la misma secuencia comparte una galleta con Estela. Es decir, la racionalización llega a su punto álgido, pero no sucede con la marca americana.

Tras varios capítulos en los que se ha insertado la marca, en el capítulo nueve "Un punto en el radar", se crea una historia que gira en torno a ella. Ulises está lleno de golpes y usa la botella para calmar la hinchazón. Ainhoa le pregunta si no se la va a beber, pues debe ser de las pocas que queda en el mundo. Él le dice que no tiene nada que celebrar. Acuerdan que ella la guardará y que cuando tenga algo que celebrar la beberán juntos.

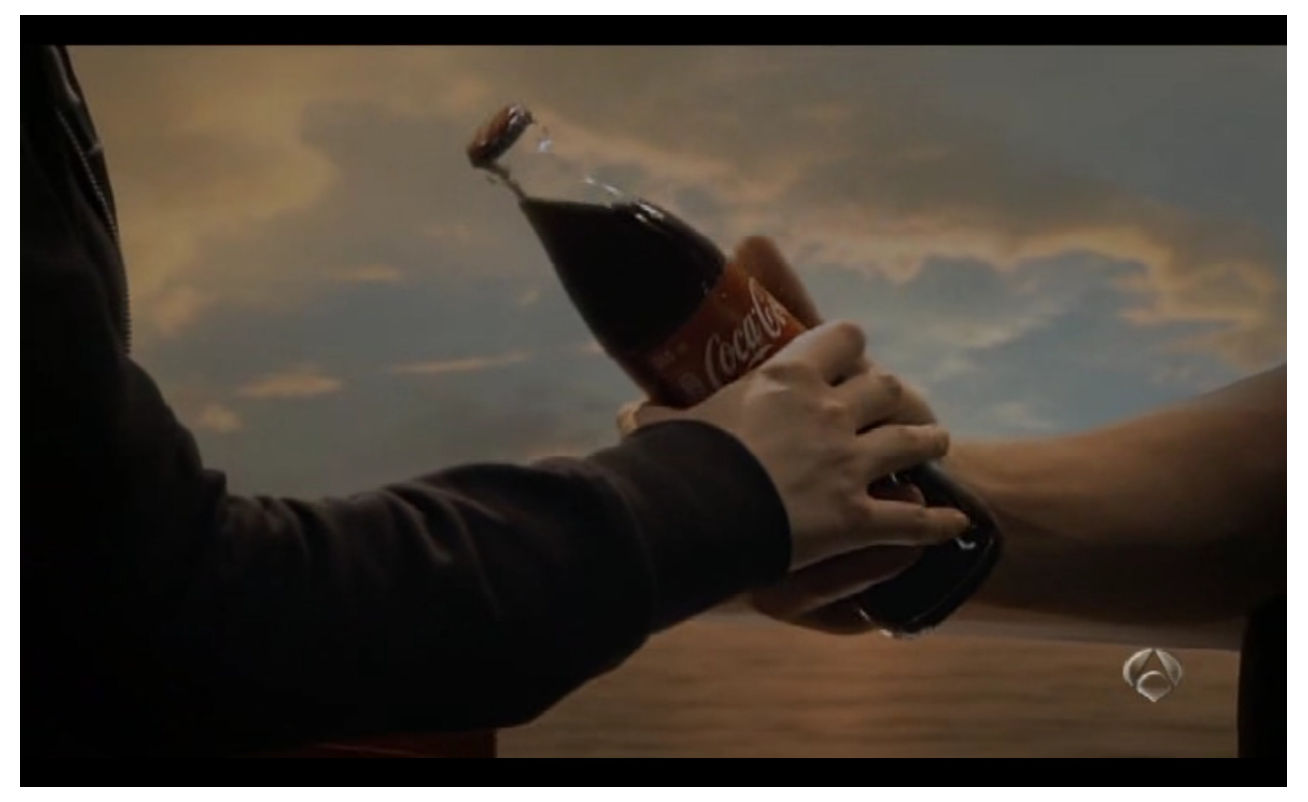

En esta misma entrega, el capitán y el primer oficial inspeccionan un yate abandonado. Alguien se ha dejado sin terminar esta bebida. 


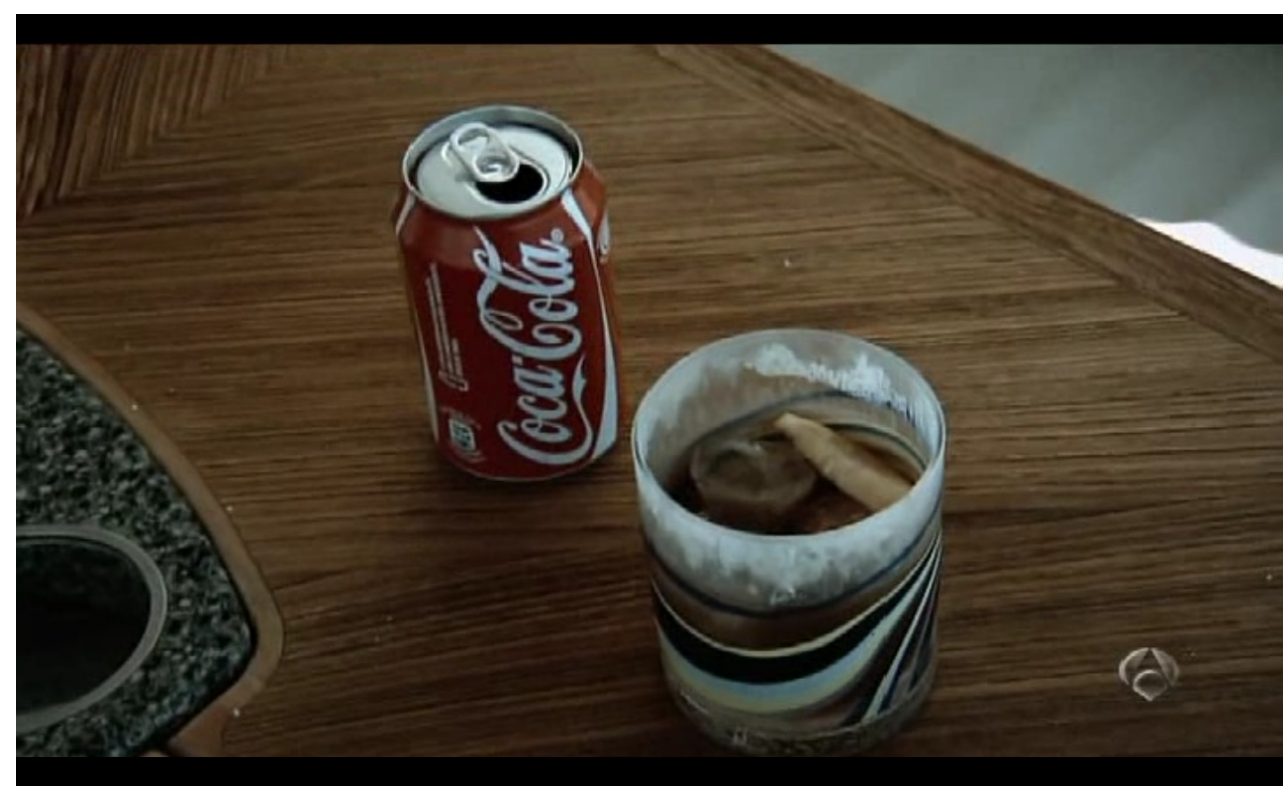

La trama desarrollada en torno a la bebida americana y que simboliza la conexión entre Ainhoa y Ulises continúa en el siguiente capítulo. En "Niebla", Ulises y Gamboa se han perdido en el mar. Ainhoa emplea el altavoz del barco para lanzarle un mensaje a Ulises: "tiene la última Coca-cola". Por esa razón, debe encontrar el camino de vuelta y ese será un motivo de celebración.

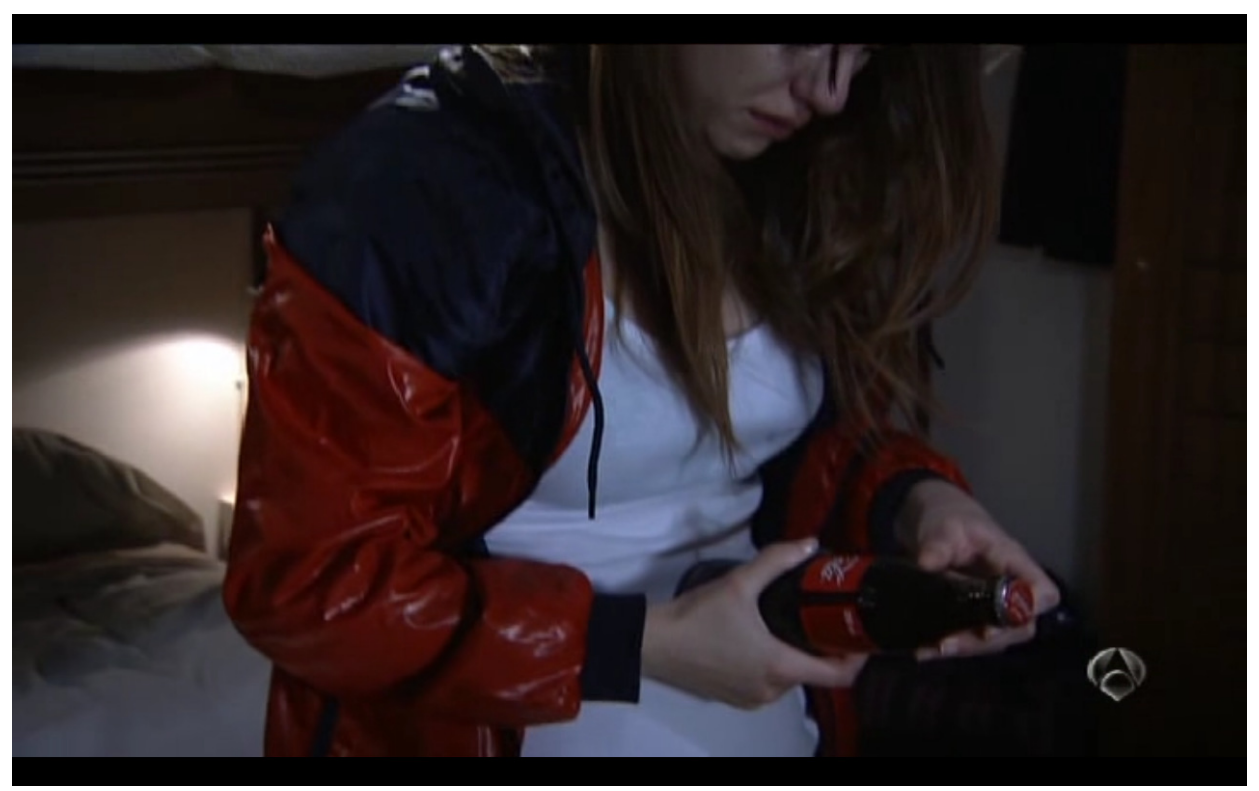

En el undécimo episodio, "La ley del mar", Ainhoa quiere abrir la botella de Coca-cola. Ulises está vivo y eso es algo para conmemorar. Él no quiere, 
prefiere esperar. De modo que la hija del capitán guarda la bebida y la trama en torno a esta marca continúa abierta.

En este mismo episodio, Estela sufre ansiedad. Necesita estar sola, por ello acude a la zona de ocio del barco en donde pone música para relajarse. En este escenario, formando parte del decorado se integra la nevera de la marca de bebidas.

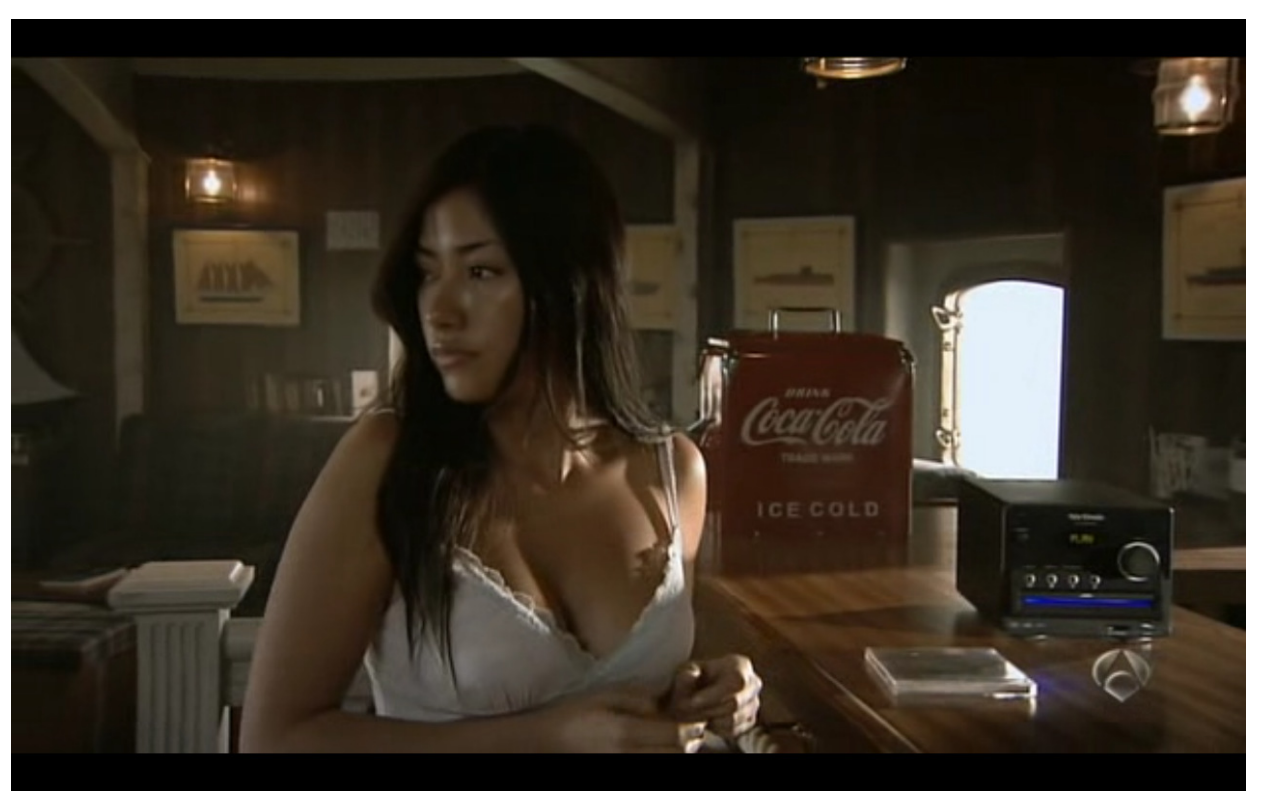

La historia entre Ulises, Ainhoa y la Coca-cola no llega al final de la temporada. Se resuelve en "El hombre de Liverpool", el penúltimo capítulo. Ulises ha sido detenido y se encuentra cerrado en la bodega del barco. Ainhoa se esconde en una caja de madera para poder verlo. Pero no va sola, guarda la Coca-cola. Ulises echaba de menos la tierra, ella lleva sacos de arena para poder plantar algo. Por lo que ya tienen algo que celebrar. En la próxima escena que se vuelve a mostrar la bebida han plantado lechugas, tomates... y se han bebido el refresco. 
De modo que, se aprovecha el recurso unresolved sexual tension ${ }^{7}$ entre los protagonistas y la expectación de esas escenas para integrar la marca, aunque esta tensión se acaba resolviendo más tarde que la de la Coca-cola.

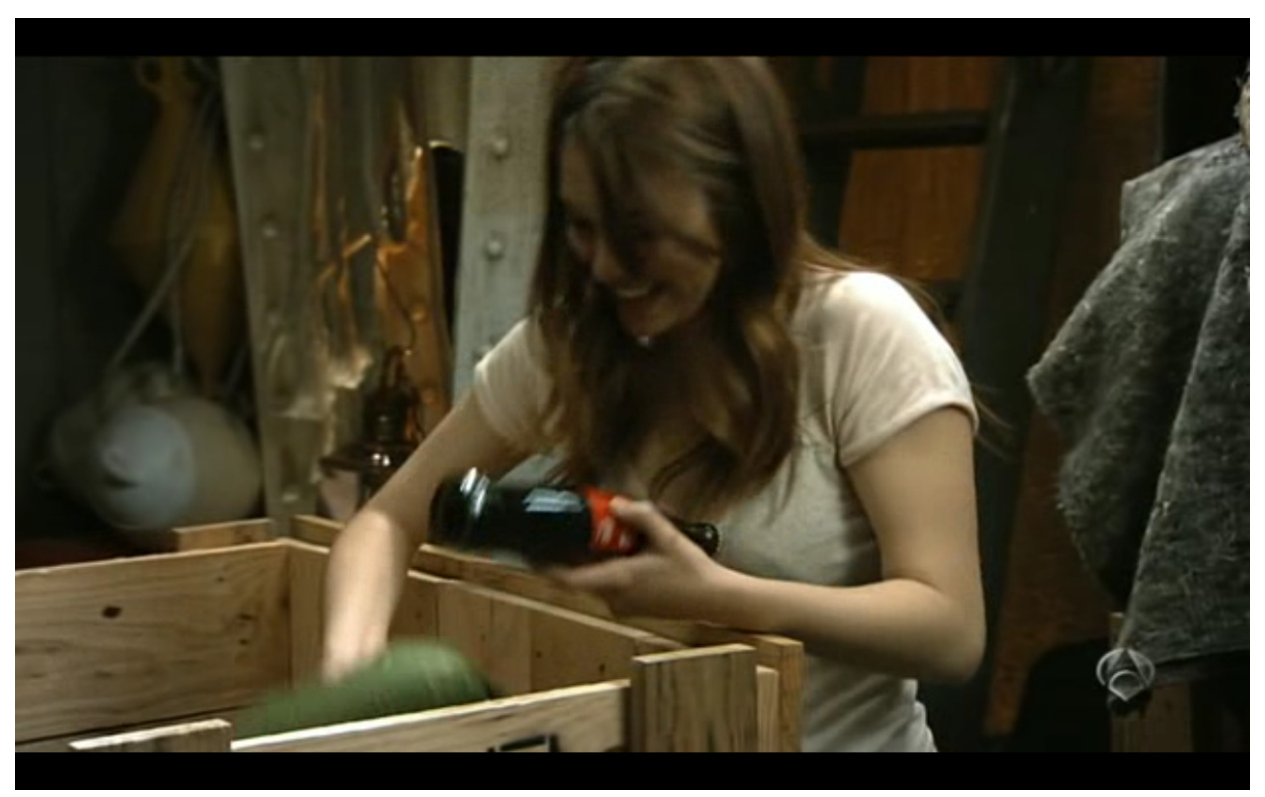

Por último, en relación al análisis, debe destacarse que muchos emplazamientos tuvieron un doble impacto. Cada lunes, antes de la emisión de una nueva entrega de la serie, se mostraba un resumen de lo sucedido en el capítulo anterior. Asimismo, debe señalares que en todos los capítulos se identifica en pantalla el emplazamiento publicitario (al principio, al final o tras la publicidad).

\subsection{De la pantalla a la red}

7 Tensión sexual no resuelta hace referencia a la química presente entre dos personajes aunque por determinadas circunstancias nunca suceda nada entre ellos (Pandey, 2005, p. 268). Se considera que un personaje mantiene con otro una tensión sexual no resuelta cuando ambos sienten una fuerte atracción por el otro, más o menos evidente, pero no es consumada. 
La introducción de los términos "Coca-Cola y El Barco" en el buscador de Facebook ha devuelto la existencia de 6 grupos creados con motivo de la presencia de la marca en la ficción ${ }^{8}$ :

1. El Barco, el único lugar donde solo Coca-cola perdura (creado el 22 de marzo de 2011) ${ }^{9}$.

2. Yo también creo que en El Barco está la fábrica de Coca-cola (28 de febrero de 2011) ${ }^{10}$.

3. ¿Cuándo se acabará la Coca-cola en la serie El Barco? (29 de septiembre de 2011) $)^{11}$.

4. ¿Cuándo se acabarán las Coca-colas de El Barco? (1 de octubre de 2012) ${ }^{12}$.

5. Se acabará el mundo pero seguiré teniendo Coca-cola (7 de noviembre de 2011) $)^{13}$.

6. ¿De dónde sacan las Coca-colas en El Barco? (22 de febrero de 2012) $)^{14}$.

${ }^{8}$ Búsqueda realizada el 19 de octubre de 2012.

9 http://www.facebook.com/pages/El-Barco-el-\%C3\%BAnico-lugar-donde-solola-coca-cola-perdura/173321136053393

10 http://www.facebook.com/pages/Yo-tambien-creo-que-en-el-barco-esta-lafabrica-de-coca-cola/191576867542765

11 http://www.facebook.com/pages/CUANDO-SE-ACABARA-LA-COCA-COLAEN-LA-SERIE-DE-EL-BARCO/122365057866095

12 http://www.facebook.com/pages/C\%C3\%BAando-se-acabaran-las-cocacolas-en-El-Barco/220538108005978

${ }^{13}$ http://www.facebook.com/pages/Se-acabara-el-mundo-pero-seguir\%C3\%A9teniendo-coca-cola/224263917640143 
Como se pueden ver, son grupos que cuestionan la presencia de una marca del sector bebidas y alimentación en una serie cuya trama gira en torno a la escasez a la que sus personajes deben hacer frente.

\section{CONCLUSIONES}

Tras el análisis del product placement de Coca-cola en El Barco, se aprecia como las marcas se integran en la ficción incluso llegando a adaptarse el guión a ellas.

Es decir, los guionistas han escrito una historia para poder insertar la marca de forma natural y reforzar su posicionamiento aprovechando la atracción de los dos principales protagonistas. Además, a través de la interacción con el resto de la tripulación se ha vinculado a momentos de ocio y de disfrute.

Coca-cola es felicidad. Por eso, cuando los personajes se encuentran pasando el rato, ya sea en el bar, la cubierta o el almacén, beben este refresco. En el caso de Ulises y Ainhoa, la bebida se convierte en su lazo. La trama original de la serie manifiesta como el mundo que la tripulación conocía ha desaparecido. Por ello, hay que guardar la última Coca-cola y beberla en una ocasión especial. Para Ulises y Ainhoa, estar juntos es más motivo suficiente.

Desde este punto de vista, se confirma la hipótesis de partida: Coca-cola emplea esta fórmula publicitaria para reforzar su posicionamiento en la mente del consumidor.

Se aprovecha la trama de la serie y las historias que sus personajes viven para reforzar la promesa de la bebida: felicidad.

14 http://www.facebook.com/pages/De-donde-sacan-las-coca-colas-en-elbarco/374937962518063 
Si bien, teniendo en cuenta el mismo argumento de la serie, se abre una futura línea de investigación para conocer como los guionistas han integrado esta marca en las siguientes temporadas de las series. El tema de la ficción es el que puede perjudicar los emplazamientos y que el espectador los perciba como opuestos al natural o contradictorios tal y como se ha percibido en los grupos creados en la red social Facebook.

A comienzos de 2012, El Barco se convirtió en la serie más seguida en internet con medio millón de seguidores en Facebook y más de 100.000 en Twitter (FAPAE, 2011. p. 126). Siendo además una de las primeras series en establecer una estrategia en redes desde su estreno en televisión, creando los "twittersodios". Es decir, los primeros episodios de una serie española vía twitter.

De modo que la publicidad en la ficción, no es solo una fórmula con ventajas derivadas de las propias características de la serialidad o relegada a la pequeña pantalla. Sino que además, se convierte en una oportunidad para estar presente a través de distintas plataformas (redes sociales, internet, móvil, etc.).

\section{BIBLIOGRAFÍA}

Antena 3 (2011). Informe Anual y Responsabilidad Social Corporativa 2011. [Recuperado 12-102012]

en http://www.grupoantena3.com/a3document/2012/04/24/DOCUMENTS/00 010/00010.pdf

Baños González, Miguel y Rodríguez García, Teresa C. (2012). Imagen de marca y product placement. Madrid: ESIC Editorial.

Bardají, Javier y Gómez, Santiago (2004). La gestión de la creatividad en televisión. El caso de Globo Media. Pamplona: Ediciones Universidad de Navarra (EUNSA).

Del Pino, Cristina (enero-diciembre 2006). El 'brand placement' en seis series españolas. De Farmacia de guardia a Periodistas: un estudio empírico. Revista Latina de Comunicación Social, año 9, 2ª época, 61, Tenerife. 
[Recuperado

15-10-2012]

en

http://www.ull.es/publicaciones/latina/200617delPino.pdf

Del Pino, Cristina y Olivares, Fernando (2006). Brand placement: integración de marcas en la ficción audiovisual: evolución, casos, estrategias y tendencias. Barcelona: Gedisa.

El Publicista (2012). El publicista de la publicidad, la comunicación y el marketing. Extra Marcas 2012. Madrid, pp. 4-12.

España. Ley 7/2010, de 31 de marzo, General de la Comunicación Audiovisual. 1 de abril de 2010, №79, p. 30157.

FAPAE (Federación de Asociaciones de Productores Audiovisuales Españoles) (2011). Memorial anual 2011. [Recuperado 22-10-2012] en http://fapae.es/archivos/memoria2011/CASTELLANO/index.html

Fórmula TV (26-04-2011). El barco' despide su primera temporada como serie revelación del 2011. [Recuperado 15-10-2012] en http://www.formulatv.com/noticias/19384/el-barco-despide-primeratemporada-serie-revelacion-2011/

García de Castro, M. (2002). La ficción televisiva popular. Una evolución de las series de televisión en España. Barcelona: Editorial Gedisa.

GECA (Gabinete de estudios de la comunicación audiovisual) (2011). Estudio de imagen GECA 2011. [Recuperado 15-10-2012] en http://www.atresadvertising.com/a3document/2011/12/26/DOCUMENTS/ 00001/00001.pdf

IAB Spain y Pwc (2011). Estudio de inversión en publicidad digital IAB-Pwc. Total año 2011. [Recuperado 22-10-2012] de http://www.iabspain.net/wpcontent/uploads/downloads/2012/05/Estudio inversion publicidad IAB Spain 2011.pdf

Infoadex (2012): Resumen Estudio Infoadex de la Inversión Publicitaria en España 2012. [Recuperado 21-10-2012] de http://www.infoadex.es/RESUMEN\%202012.pdf

Medina, Mercedes (coord.) (2008). Series de televisión. El caso de Médico de familia, Cuéntame cómo pasó y Los Serrano. Madrid: Ediciones Internacionales Universitarias. 
Pandey Ashish (2005). Academic Dictionary of Fiction. Gyan Books.

Web Oficial de Coca-cola: http://conoce.cocacola.es/conocenos. [Recuperada 21 -10-2012]

Web Oficial de El Barco. http://www.antena3.com/series/el-barco/. [Recuperada 21 -10-2012]

Web Oficial del Instituto de la Felicidad de Coca-cola: http://www.institutodelafelicidad.com/instituto. [Recuperada 22 -10-2012] 